\title{
University Governance: Empirical Evidence from Morocco
}

\author{
Khaoula Dobli Bennani", Khalid Ayad, Mostafa Elhachloufi \\ Department of Economics and Management, Hassan II University of Casablanca, Morocco
}

Received March 4, 2021; Revised April 14, 2021; Accepted May 16, 2021

\section{Cite This Paper in the following Citation Styles}

(a): [1] Khaoula Dobli Bennani, Khalid Ayad, Mostafa Elhachloufi , "University Governance: Empirical Evidence from Morocco," Universal Journal of Educational Research, Vol. 9, No. 6, pp. 1188-1196, 2021. DOI: 10.13189/ujer.2021.090608.

(b): Khaoula Dobli Bennani, Khalid Ayad, Mostafa Elhachloufi (2021). University Governance: Empirical Evidence from Morocco. Universal Journal of Educational Research, 9(6), 1188-1196. DOI: 10.13189/ujer.2021.090608.

Copyright $\mathrm{C} 2021$ by authors, all rights reserved. Authors agree that this article remains permanently open access under the terms of the Creative Commons Attribution License 4.0 International License

\begin{abstract}
In recent years, the concept of university governance has become a determining factor in the quality of higher education in different countries and possibly has an impact on their economic and social development. The study aimed to identify the state of governance of Sidi Mohamed Ben Abdellah University according to the views of students. The researchers used the descriptive method in the study. The population of the study consisted of all the students of Sidi Mohamed Ben Abdellah University for the $2017 / 2018$ academic year. The study sample was random and had 947 members. The researchers used a questionnaire to collect the data to achieve the study's objectives. It was composed of (20) distributed elements in the fields of study. The results indicated that within the University of Fez, there is a very moderate application of the principles of governance, which may also be the case for other Moroccan universities. This may well be the source of the failure of our higher education system.
\end{abstract}

Keywords University Governance, Higher Education, Good Governance, Morocco

\section{Introduction}

The national and international environment shows a positive trend towards adopting the concept of governance where conferences have been held and studies have been implemented that recommend the application of governance and its principles in institutions of higher education, especially since governance is a strategic force that supports the achievement of the higher education vision-mission. Delanty [1].

In recent years, the concept of university governance has become a determining factor in the quality of higher education in different countries and possibly affecting their economic and social development. Nevertheless, Moroccan universities have faced several obstacles that limit the application of governance, related to the mechanisms of transparency, decision-making, government, steering, sharing, exchange of procedures that need to be revisited to achieve effective and efficient management. CSFRS [2]. Moreover, a few empirical studies were dedicated to this subject. Trying to fill this gap, we present this paper, which aims to evaluate the degree of application of the principles of university governance in Morocco, taking the case of Sidi Mohamed Ben Abdellah University- Fes.

To present the state of governance at Sidi Mohamed Ben Abdellah University according to the views of students, we chose the descriptive method because it corresponds to the nature of the study and allows us to interpret its results.

The aim of this study is to find out if we have good governance in Moroccan universities, taking the case of the Sidi Mohamed Ben Abdellah University of Fez.

Therefore, our objectives are:

- Determinating the degree of application of governance at Sidi Mohamed Ben Abdellah University of Fez from a student's perspective.

- Identifying the criterion (principle) that most affects university governance. 
In our article, to present the state of governance at Sidi Mohamed Ben Abdellah University, we focused on the principles of good governance generally accepted by global groups and programs such as the World Bank, the Asian Development Bank, the African Development Bank, and the United Nations Development Program.

We will illustrate the state of university governance through the following principles:

- Fighting corruption.

- Equity and equal opportunity.

- Participation.

- Effectiveness and efficiency.

- Regulation.

\section{Literature Review}

The topic of governance has grown considerably in the last two decades, and research on higher education governance continues to increase quickly. The number of articles indexed in the Scopus database dealing with higher education governance exceeds 88,784 articles, including more than 12,281 just in 2020 , demonstrating the growing interest in the subject.

Governance is" currently a key issue not only for higher education institutions but for society as a whole". Kennedy [3]. Governance plays a key role in universities. It has "become a major leverage tool for improving quality in all aspects of higher education". Santiago [4].

Previous studies have shown the existence of real problems in governance in the several levels and aspects of higher education in the Arab World. That includes low levels of autonomy and transparency, slow government bureaucracies, lack of independent national accreditation agencies, centralized admission procedures, unaccountability of institutional actors to boards of directors or stakeholders other than public authorities and political influence in the selection of senior Higher Education Institutions (HEIs) staff. Bouri [5].

Despite the efforts and colossal sums devoted to improving higher education, the system still suffers from poor governance and related problems:

The higher education system in the Arab world, despite all the efforts and government expenditure to improve higher education governance, reflects a deeper level of challenges and problems. Habchi [6].

Certainly, efforts have been made to improve university governance in two aspects: strengthening the power of the executive authority and increasing the presence of external members in supervisory bodies. Bouri [5].

However, given the scale of the problem, it is hard to imagine any real change in the short term, as "all Arab states suffer, in variable degrees, from the same syndrome of political reticence toward granting more autonomy and freedom to their HEIs". Bouri [5].

With the advent of international ranking tables and greater competitiveness, the deficiencies of Arab universities are becoming manifest. Badran [7].In Arab universities, it seems that there are deficiencies in all the principles of good governance: low autonomy, low transparency, absence of accountability, and absence of the culture of evaluation.

Two important principles of governance are autonomy and accountability. The academics and university leaders like often talk about the lack of autonomy in the Arab universities, but they hardly talk about the accountability. This is one of the most dazzling paradoxes of the higher education in the Region. This could be a consequence of the regional culture, which does not consider the accountability and the evaluation. The universities leaders and academics rather talk about their rights than their obligations. They ignore that autonomy should be coupled with accountability.

This fact is confirmed by Waterbury [8]. According to him, autonomy must be coupled with an analysis of accountability. They are two sides of one coin. All forms of autonomy are accompanied and constrained by forms of accountability. He points out: "All other components of governance are of significantly less importance than these two. Finding the right equilibrium between autonomy and accountability is the most crucial part of good governance. Waterbury [8] contends that the fundamental question that we must ask concerning autonomy is "autonomy to do what?" He argues that there is nothing intrinsically good or bad about autonomy. It all depends on what one is trying to achieve. Full autonomy in the real world does not exist. No institution can do as it pleases. This is a very intelligent remark because many Arab university officials (including Moroccans) invoke the fact of a lack of autonomy to resist any change and to not make any real reforms. One can imagine that many of them only want to take advantage of autonomy to achieve their own ends. Autonomy is not and should not be absolute. It should always be linked to accountability and responsibility.

Hillman and Baydoun [9] argue that university autonomy is regarded as a threat for some Arab countries. They lamented that many Arab governments perceive universities as a danger and a threat because they severely limit the autonomy of universities not only by limiting their funding but also by interfering directly in the structure, appointments, and management of these institutions. In the same way, Hunaiti [10] advances that most Arab governments fully control financial expenditures and the appointment of senior staff in public universities and the appointment of senior staff in private universities.

Transparency is also one of the most important principles of governance. In the field of higher education, it plays a key role in the relation with partners, donors, and society .It is the cornerstone to fight corruption in the field.

Many empirical studies have been conducted in the Arab region about the university governance, mainly in Arabic.

Kentab [11] conducted a study that aims at identifying the degree of application of governance requirements at King Saud University from the point of view of the faculty 
members through transparency, accountability, organizational structure, laws and regulations, and justice. The study reached several conclusions concerning the degree of application of governance requirements at King Saud University from the point of view of faculty members. The general arithmetical mean of transparency is average, the general arithmetical mean of accountability is average, the general arithmetical mean of the area of organizational structures is high, and that of the area of regulations and laws is high.

In the Maghreb, despite these sometimes-modest attempts at change since national independence, the general trend in university governance in the Maghreb countries has shifted significantly towards a certain degree of autonomy that has varied from one country to another. Benjelloun [12].

In Morocco, the new Constitution of 2011, which comes in the context of the "Arab Spring", establishes good governance as a fundamental principle in the process of consolidating and strengthening the institutions of a modern State. In this regard, good governance has occupied a central place in the new Constitution; an entire chapter has been devoted to it. Good governance is concerned with the principles of transparency, accountability, fighting corruption, ethics, and Accountability.

The Moroccan code of good governance practices for public enterprises and establishments comes in a context marked by the adoption by Morocco of the new Constitution and intended to reflect its aspiration and implant the culture and practice of good governance:

This code has five dimensions regarded as pillars for good governance practices for corporations and public institutions that underscore transparency, accountability, inclusiveness, stakeholder participation, and assigning roles to the State Institutions and within Institutions to Governing bodies. Public Universities in Morocco adhere to this code and must report on a yearly basis. Jaramillo [13].

On the other hand, the National Charter of Education and Training underlined the importance of governance in the Moroccan education system and devoted a whole section to it.

However, in reality, are these principles of good governance well respected? To what extent?

According to Benjelloun [12], several attempts have been made to assess stakeholder participation in Maghreb university governance. The World Bank's benchmarking report assessing governance through the scorecard methodology is perhaps the most comprehensive to date. World Bank [14]. It confirms that on the dimension of participation, Moroccan universities scored highest among Maghreb countries. The self-perception results obtained from stakeholders were even higher on this dimension than reported by the questionnaires. On the dimension of autonomy, stakeholders in Moroccan universities again perceived their autonomy as greater than indicated in the questionnaires. Overall, these results indicate a significant degree of satisfaction among Moroccan university stakeholders with their involvement in university affairs.

In Morocco, unlike the Arab countries of Middle East, there are few empirical studies on this very controversial and very sensitive topic, and for this reason, perhaps that researchers fear to approach this taboo topic. The existing studies remain very general and do not go deep into the problem in the university system and do not tackle the question of transparency, accountability, evaluation , quality in the higher education, the performance of the university leaders and faculty, the corruption in the field, the recruitment of professors...etc. For instance, Boumahdi [15] conducted a study about the research and governance at Mohamed V University. The results revealed a very marked deficit in terms of communication, particularly for governance and research.

Failure in the governance system and lack of transparency naturally leads to the corruption that has heavy consequences:

Corruption and poor governance are recognized as major obstacles to the realization of the right to education and the achievement of global development goals. Corruption not only distorts access to education but also affects the quality of education and the reliability of research findings. Transparency International [16]. Corruption is a real threat to the quality and credibility of the university system. It might affect all aspects of the educational system

In Morocco, a previous study by Transparency Maroc was conducted about transparency in universities. Barkallil [17]. This study, although it dates back to about 20 years, is one of the few studies that it tackled in depth the problem of corruption in Moroccan universities. The author of the report confirmed that the issue of transparency at the university is a very sensitive subject and is still taboo. She perceived this embarrassment to talk about it and to bring a personal testimony in many of the interlocutors. Usually, students do this more spontaneously than other stakeholders do. The administrators are the most reluctant to testify and the situation becomes more complicated when the establishment experiences a difficult economic situation because of a "case" or a "scandal" .The managers of the establishments concerned show a great deal of mistrust towards investigators. Debbagh [18]. The results of the survey show that $61.2 \%$ of students, $74 \%$ of teachers, and $71 \%$ of administration staff say they have heard of corruption or similar practices in their own institution, meanwhile $79.6 \%$ of students, $78.3 \%$ of teachers, and $78.4 \%$ of administration staff claim to have heard of it in other academic institutions. Debbagh [18].

It seems that corruption is so prevalent that some authors defend the idea that corruption in Morocco has been used and instrumentalized as a mode of governance to achieve certain objectives. Barkallil [17].

The Transparency Morocco press release published on 
Thursday, January 28, 2021, affirms: "Perception Index shows that Morocco persists in occupying a place that can be considered an area of chronic corruption. Besides, over the past 4 years, the country has been on a worsening trend - which is corroborated by the results of other surveys (such as The Global Corruption Barometer)".

In 2020, Morocco's ranking deteriorated by six places and one point compared to 2019 with a score of 40 out of 100 and is ranked 86 out of 180 countries. According to "Transparency Maroc, Barkallil [17]", this indicates the acute level of corruption in our country. Except for the anti-corruption rhetoric, which has completely lost its credibility, there is no positive indication of a real will to fight corruption effectively.

Nevertheless, few empirical studies were dedicated to this subject in Morocco. Trying to fill this gap, we present this paper, which is one aims to assess the degree of application of the principles of university governance in Morocco.

\section{Methodology}

\subsection{Type of Investigation}

The study adopts the paradigm of quantitative research. It has an exploratory investigative scope since there is little background and very little information on the topic treated.

We adopted a descriptive and analytical method to achieve the objectives of the study, which consist in evaluating the degree of application of university governance requirements through the following principles: Fighting corruption, equity and equal opportunity, student's participation, effectiveness and efficiency, regulation.

\subsection{Population}

The population of the study consisted of all the students of Sidi Mohamed Ben Abdellah University for the 2017/2018 academic year. Ministry of Higher Education [19]. The data collection spanned over a period of 5 months (from January 2018 to May 2018).

The study sample was random and had 947 members. The researchers used a questionnaire to collect the data to achieve the study's objectives. It was composed of (20) distributed elements in the fields of study.

\subsection{Sample and Data Collection}

The data collection was made during 2017-2018 academic year, using a semi-directive survey questioning students. Because of the lack of a sampling frame containing a complete list of observation units, the empirical sampling method, more precisely the quota method, was used for the selection of the sample. As a result, $1 \%$ of university students were randomly taken or
947 respondents.

The data were processed in SPSS version 20, to obtain the methodologically proposed correlation. Its discussion is approached under scientific argumentation.

\subsection{Analyze of Data and Scope of the Study}

Based on the principles of university governance cited above, a set of axes has been defined to establish the questionnaire addressed to the targeted sample. Each axis includes questions to assess the presence and application of university governance principles.

\subsection{Axes and Questions of the Study}

- Good governance: What is the principle of governance that you need the most in your university to have good governance?

- Fighting corruption: To what extent the acts of corruption were spread in your university? What are the reasons for the existence of these corrupt practices? And what measures and actions to implement to fight them?

- Equity and equal opportunity: When did these corrupt practices take place? Did they have an influence on equity and equal opportunity of the students?

- Participation in decisions: Do you participate to organizations and committees in your institutions? What are the reasons for your low participation?

- Effectiveness and efficiency: How effective are your university/institution's stakeholders? How satisfied are you with the services and resources of your university/institution?

- Regulation: To what extent are you familiar with the internal regulations of your institutions? Does the French language present an obstacle to learning your lessons? If so, with what language do you prefer to study?

\section{Findings}

\subsection{Good Governance}

What is the principle of governance that you need the most in your university to have good governance?

The result shows that $30.8 \%$ of the students surveyed believe that to have good governance, equity and equal opportunities must first be guaranteed, followed by $26.5 \%$ who opted for the fight against corruption as a determining factor of governance.

\subsection{Fighting Corruption}

To what extent the acts of corruption were spread in your university? What are the reasons for the existence of these 
corrupt practices? And what measures and actions to implement to fight them?

According to the results, we note that the majority of students at Sidi Mohamed Ben Abdellah University of Fez find that corruption practices are quite widespread (40.7\%) and $31.8 \%$ of them find them very widespread. However, only $6.9 \%$ find these acts rare and $1.6 \%$ find them non-existent, which leads us to conclude that, according to the opinion of the students, there is a real problem of corruption within the higher institutions of Fez.

Student responses revolve around actions: (Choose rigorously officials/ Punish offenders/ Intensify controls).

\subsection{Equity and Equal Opportunity}

When did these corrupt practices take place? Have they an influence on equity and equal opportunity of the students?

This part verifies whether the existence of corrupt practices has an influence on integrity and justice on strategic, educational, and executive decisions.

The results show that corruption harms equity and equality of opportunity of students (there is a blatant dependence between these two variables). In that sense, since there is corruption, there is inequity and inequality of opportunity. According to the results, an overwhelming majority believe that fairness does not exist in written examinations and in enrolment with percentages of $91.0 \%$ and $77.9 \%$ respectively. The same goes for transfers of files where more than half think corruption exists. However, few students believe in the existence of corruption during oral examinations.

\subsection{Participation in Decisions}

Do you participate to organizations and committees in their institutions? What are the reasons for your low participation?

The results show that only 53 responded positively, among 947 students surveyed, to the question about their participation on student committees, which should call our attention to the root causes of this result.

The results show also that the main reasons why students do not participate in these committees are the lack of added value brought by these organizations to student life and their lack of involvement in strategic and educational decisions (with percentages of $31.8 \%$ and $24.7 \%$ respectively). This logically affects their interest in this type of organization $(23.1 \%$ are not interested in these student committees).

\subsection{Effectiveness and Efficiency}

How effective are your university/institution's stakeholders? How satisfied are you with the services and resources of your university/institution?

The results show that few students consider that the work of the six stakeholders (Presidency, Administrative Body, Faculty, Dean's office, Student Committee, Scientific Committee) is effective, the majority of the responses revolve around (Moderately effective/ less effective/ Ineffective). It should also be noted that almost a quarter of the students interviewed have no idea about the effectiveness of the scientific committee.

Concerning university services, the results show that, except for the catering service and the scholarship service, where $18.6 \%$ and $22.6 \%$ respectively of the students surveyed are satisfied, most are dissatisfied with the services and resources provided. Boarding school is the most frustrating service for students with a percentage of $31.1 \%$ who responded with absolute dissatisfaction, followed by the library with a percentage of $30.5 \%$.

\subsection{Regulation}

To what extent are you familiar with the internal regulations of your institutions? Does the French language present an obstacle to learning your lessons? If so, with what language do you prefer to study?

According to the results, $38.5 \%$ of the 947 students questioned do not know the internal regulations of their institutions.

In this section, we tried also to find out if the students have a problem with the French language, the language of instruction in the scientific and economic disciplines in Morocco, and with which language they prefer to study.

According to the results, we found that $56.5 \%$ of students surveyed have no problem studying in French, the rest says otherwise. $44.4 \%$ of them prefer to study in Arabic.

\subsection{Impact Analysis}

After analyzing the degree of application of the principles of governance at the Sidi Mohamed ben Abdellah University in Fez, we tried to identify the criterion (principle) that most affects university governance, by using the SPSS software.

- In the first step, we decided to see the chances of having good governance without including any criteria influencing governance: this is called the zero model.

The zero model does not include any predictor of governance risk. It makes it possible to determine the chances (a priori) of the existence of good governance. (The reference category is to have good governance).

This model only includes the constant: Logit $($ Governance Judgment $)=\mathrm{b} 0$.

It is a question of showing what the risk is for good governance to exist without taking into account other characteristics (variables). The accuracy rate, in this case, is $87.5 \%$, which means that in $87.5 \%$ of the cases, the model did not err. 
Table 1. Variables in the equation

\begin{tabular}{|c|c|c|c|c|c|c|c|}
\hline & & B & S.E & Wald & df & Sig. & Exp (B) \\
\hline Step 0 & Constant & -1.950 & 0.098 & 392.599 & 1 & 0.000 & 0.142 \\
\hline
\end{tabular}

For this null model, the logistic regression equation is: Logit (Governance Judgment) $=-1,950$. It can therefore be concluded that the model is significant.

Besides, though, $\mathrm{OR}=0.142$, we can say that for Sidi Mohamed Ben Abdellah University, whatever the characteristics affecting governance, the probability of having good governance is 0.142 .

- The second step consists of introducing the following variables to see their impact on governance and then detect the criterion having the most impact on this governance:

The variables included in the non-null model are:

- The presence of acts of corruption/

- The existence of equity and equal opportunities/

- Student membership in the student committee/

- Knowledge of the institution's internal regulations.

Table 2. Model Summary

\begin{tabular}{|c|c|c|c|}
\hline Step & $\begin{array}{c}-2 \text { Log } \\
\text { likelihood }\end{array}$ & $\begin{array}{c}\text { Cox \& Snell } \\
\text { R Square }\end{array}$ & $\begin{array}{c}\text { Nagelkerke R } \\
\text { Square }\end{array}$ \\
\hline 1 & $548,137^{1}$ & 0,159 & 0,301 \\
\hline
\end{tabular}

The non-null model is used to determine the subsequent chances of good governance considering its characteristics. Including the variables affecting governance increases the significance of the model.

Collectively, the predictors of the model explained between $15.9 \%$ and $30.1 \%$ of the variability in the risk of good governance.

Besides, all these significant variables affect the risk of having good governance at a rate of $30.1 \%$.

When we include the characteristics influencing governance, the percentage of the model's significance increases from $87.5 \%$ to $90.1 \%$, a significant improvement in the quality of the model by $2.6 \%$.

Finally, we found that the variables related to the existence of equity and equal opportunities, student membership in the student committee, knowledge of the institution's internal regulations are not significant so they do not affect good governance.

However, the variable of the presence of acts of corruption is significant so it directly affects good governance.

\section{Discussion}

In the study, we came to several conclusions regarding

\footnotetext{
1 Estimation terminated at iteration number 20 because maximum iterations has been reached. Final solution cannot be found.
}

the degree of application of governance requirements at Sidi Mohamed Ben Abdellah University in Fez from the perspective of students:

\subsection{Fighting Corruption}

According to students' responses, corruption practices are quite widespread and very widespread, which leads us to conclude that there is a real problem of corruption within the higher institutions of Fez. At the general level, this was also confirmed by the Anti-Corruption Association, which is ranking Morocco 86th out of 180 corrupt countries. Transparency International [16]. This corruption perception index shows that Morocco continues to occupy a place that can be considered an area of chronic corruption and that over the last 4 years the country is in a trend of worsening. This leads us to wonder whether the choice of officials is being made properly and whether there are controls and sanctions for any corrupt act. Furthermore, after analyzing the criterion that most impacts university governance, we found that the variable of the presence of acts of corruption is significant, so it directly affects good governance. However, compared to the result of the previous study of Transparency Maroc, Barkallil [17], it seems that the rate of students who think that corruption in the university of Sidi Mohamed Ben Abdellah is low (40.7\% versus $61.2 \%)$. This difference can be partially explained by the time difference, and by the difference in the sample and its size. We believe that there is no improvement in terms of combating corruption in Moroccan universities, perhaps; on the contrary, there is deterioration at this level, as evidenced by the deterioration in the ranking of Morocco according to the reports of Transparency. That is why action must be taken to combat first this corruption and increase transparency as a necessary condition to put an end to acts of transgression and fraud.

\subsection{Equity and Equal Opportunity}

Equity and equal opportunity are seen as prerequisites for the establishment of good governance in Moroccan universities. This principle achieves the criteria related to the adoption of regulations, laws, and participation and that without equity and equal opportunity; governance will not succeed in achieving its objectives. Mahmoud [20].

Students believe that there is an unequal opportunity because of corruption. The vast majority believe that fairness is not found in the written exams and enrolment, but few students believe in the existence of corruption 
during the oral exams. This result seems strange because the probability of tampering and abuse, and thus unequal opportunities, is greater in oral examinations than in written exams, in which, at least, it is possible to refer to the written paper when necessary.

\subsection{Effectiveness and Efficiency}

Effectiveness and efficiency should also be ensured, but the reality shows the work of the stakeholders of the university (Presidency, Administrative Body, Faculty, Dean's office, Student committee, Scientific committee) is moderately effective, less effective, even ineffective. These findings given by students generate questions about the proper functioning of these parts and their commitment to meet the needs and requirements of the students and ensure their satisfaction. Furthermore, a quarter of the students interviewed have no idea about the effectiveness of the scientific committee, this is maybe due either to the lack of information or the lack of interest of these students in this part.

Concerning university services, most of the students are dissatisfied with the services and resources provided.

\subsection{Participation in Decisions}

Good governance requires that stakeholders, including students, participate in decisions, as it is the cornerstone of university governance. Participation means that the opinion of all those involved in decision-making is taken into account. Mahmoud [20]. Participation aims to bridge the gap between management and the public and to create non-pyramidal forms for the practice of power that is not based on the principle of delegation, participation, and formality, but rather on the group's participation in the decision and its implementation. Shukr [21].

Law 01.00 has widened the participation of new stakeholders in the university council. The World Bank's benchmarking report, World Bank [14] confirms that on the dimension of participation, Moroccan universities scored highest among Maghreb countries. However, we think this participation is rather "formal » since there is repetitive absenteeism of some stakeholders, such as socioeconomic representatives and students. This study comes to confirm the weak participation of the students and it demonstrates the fact that students do not care about participation in university governance because they are not convinced of the benefits of participation in governance.

\subsection{Regulation}

Governance also requires a fair legislative framework. It also requires full protection of the rights of individuals, particularly in terms of control and strengthening of laws. It also requires an independent judiciary and a just political force that does not accept corruption and is characterized by justice. Mahmoud [20].

Compliance with rules and regulations ensures integrity and objectivity, to the extent that there are general rules to be invoked, and the legal framework must specify the mandate of each person belonging to the University and the responsibilities of the various committees and their respective roles. It should also determine the sanctions that apply to individuals or to some of these parties in the event of exceeding these powers or failing to perform their duties and determine the monitoring of the application of governance procedures. In this sense, students must be familiar with the internal regulations of their institutions. However, most of the students do not know the internal regulations of their institutions, which leads us to think about whether this regulation already exists and if it does, the question arises if the parties concerned share it. Meanwhile, a large percentage that cannot be neglected of the students, prefer to study in Arabic instead of the French language. This raises the question of whether higher education in Morocco should be Arabized.

In brief, the results show that the principles of governance are very moderately applied at Sidi Mohamed Ben Abdellah University in Fez. On the other hand, the results at Sidi Mohamed Ben Abdellah University of Fez show also that we must first act on the principle of fighting corruption as a primary criterion of good governance. For that reason, corruption challenges all stakeholders in Moroccan universities and invites us to review in-depth the recruitment system of the academic and administrative body, the promotion system, the governance system as a whole, and strengthen accountability. When corruption affects education, we must act quickly, end with the impunity that encourages these practices more, because it is the future of an entire nation that is at stake and has an impact on the social and economic development of our country.

\section{Conclusions}

For the first perception, the real problem of university governance is the existence of corruption that undermines the equity and equality of opportunity of students. This was perfectly demonstrated in our in-depth analysis, where the students see the corrupt practices within the university, the object of study. The latter also claims that this corruption affects their opportunities to have a fair and deserved university degree.

The root cause of this corruption may well be the inappropriate choice of officials within the university. A finding that can be detected or avoided if there are controls and/or sanctions for any corrupt act.

Another failing principle of university governance is the representativeness or participation of students in student 
committees. A failure is essentially due to the lack of benefit brought by these organizations to the careers of students without forgetting their non-participation in the strategic and educational decisions of the university; something that must be done.

The students also unfavorably assessed the effectiveness of the university's stakeholders. Furthermore, university services and resources do not meet the needs of students, adding to the perception that the distribution of positions is inadequate. This can be generated by the lack of evaluation and accountability of university staff. The practical analysis revealed that the principles of governance, specifically corruption are almost inapplicable within the University of Fez, which may also be the case for other Moroccan universities. This may well be the source of the failure of our higher education system.

Indeed, the introduction of the principles of university governance is important to ensure a better quality of university education. Nevertheless, it is only after an extension of our study that we will be able to assess the real application of these university governance requirements in Morocco. An extension of this study could encompass two other components (actors) of the internal environment of university governance, namely faculty and administrative staff.

\section{REFERENCES}

[1] Delanty G. The governance of universities: What is the role of the university in the knowledge society? The Canadian Journal of Sociology/Cahiers canadiens de sociologie. 2002 Apr 1; 27(2):185-98.DOI: https://doi.org/10.2307/3341710.

[2] Conseil Supérieur de l'Education, la Formation et la Recherche Scientifique, Mise En Euvre De La Charte Nationale D'éducation Et De Formation 2000-2013: Acquis, Déficits Et Défis, 2014.https://www.csefrs.ma/wp-content/u ploads/2017/10/Rapport-analytique.pdf

[3] Kennedy KJ. Higher education governance as a key policy issue in the 21 st century. Educational research for policy and practice. 2003 Jan; 2(1):55-70. DOI: https://doi.org/10.1023 /A:1024468018883.

[4] Santiago P, Tremblay K, Basri E, Arnal E. Tertiary education for the knowledge society. Paris: OECD; 2008. https://www.oecd.org/education/skills-beyond-school/41266 690.pdf

[5] Bouri E, Maalouf M. The impact of governance in higher education institutions on scientific research in the Arab World. In Higher Education Governance in the Arab World 2018 (pp. 65-82). Palgrave Macmillan, Cham. DOI: https://doi.org/10.1007/978-3-319-52060-5 4.

[6] Habchi A. The Role of Governments in Shaping Governance of Higher Education Institutions in the Arab World. In Higher Education Governance in the Arab World 2018 (pp. 105-130). Palgrave Macmillan, Cham. DOI: https://doi.org/
$10.1007 / 978-3-319-52060-5 \quad 6$.

[7] Badran A, Baydoun E, Hillman JR. Higher Education in the Arab World. (Eds.). (2020). Springer, Cham. Doi: 10.1007/978-3-030-58153-4.

[8] Waterbury J. Governance of Arab Universities: Why Does It Matter? In Universities in Arab countries: An urgent need for change 2018 (pp. 55-70). Springer, Cham. https://doi.org/10 .1007/978-3-319-73111-7_2.

[9] Hillman JR, Baydoun E. Review of the Roles of Governments and Universities and Their Interrelationships: An Urgent Need for Governance Reform in the Arab World. In Higher Education in the Arab World 2020 (pp. 1-79). Springer, Cham. DOI: https://doi.org/10.1007/978-3-030-58 153-4_1.

[10] Hunaiti AA. Governance and Decision-Making in Arab Universities. In Higher Education in the Arab World 2020 (pp. 109-116). Springer, Cham. DOI: https://doi.org/10.100 7/978-3-030-58153-4 4.

[11] Kentab MY. The Applicability of Governance at King Saud University in Riyadh. Universal Journal of Educational Research. 2018; 6(1):25-41. Doi : https://doi.org/10.13189/u jer.2018.060103

[12] Benjelloun W. University reform in the Maghreb countries: institutional autonomy as a lever for national development. InUniversities in Arab Countries: An Urgent Need for Change 2018 (pp. 287-293). Springer, Cham. https://doi.org /10.1007/978-3-319-73111-7_15.

[13] Jaramillo A. Benchmarking governance as a tool for promoting change. The World Bank; 2013 Washington, D.C. World Bank Group.http://documents.worldbank.org/curated /en/125381468275686170/Benchmarking-governance-as-a-t ool-for-promoting-change.

[14] World Bank. Universities through the Looking Glass: Benchmarking University Governance to Enable Higher Education Modernization in MENA. Washington, DC. (C) World Bank. 2012, https://openknowledge.worldbank.org/h andle/10986/12535 License: CC BY 3.0 IGO.

[15] Boumahdi. A,2019, Evaluation and analysis of the quality of governance, training and research in the higher education system -University of Rabat, International journal of digital economy, Abdelaziz Boumahdi, Vol. 1, No 1 (2019).

[16] Transparency International, Global corruption report: Education. Earthscan, publishing for a sustainable future, Routledge, Taylor \& Francis Group, 2013.

[17] Barkallil Nadira, La corruption à l'université, un produit de la corruption-système de gouvernance, Université de transparence, Transparency Maroc, 2002, pp. 39-44. https://transparencymaroc.ma/universite-de-la-transparence/ (accessed 28/01/2021)

[18] Debbagh Amina, Transparency University. A qualitative Survey of the main academic actors,2002, Transparency Maroc, pp. 11-36. https://transparencymaroc.ma/universitede-la-transparence

[19] Ministry of Higher Education.,Department of Statistics and Information Systems, University Statistics,2017 - Public Higher Education 2017-2018. 
[20] Mahmoud, Madiha Fakhri. (2011). Analytical study of the concept of good governance and its application requirements in Egyptian universities. Cairo, Future Journal of Arab Education, Volume XVIII, issue 72, pp. 45-144.
[21] Shukr, Abdul Ghaffar, The educational and developmental role of NGOs and cooperatives in Egypt, Cairo, Egyptian General Book Organization., 2005. 